\title{
FACILITATING STAKEHOLDER DIALOGUES ON A CARBON NEUTRAL CITY: WE NEED TO TALK ABOUT CARBON (AND AIR QUALITY)
}

\author{
EMILY PRESTWOOD ${ }^{1}$, JAMES LONGHURST ${ }^{1}$, IAN TOWNSEND ${ }^{2}$, \\ THOMAS HAINES ${ }^{3} \&$ ELEFTHERIA TSIARAPA $^{1}$ \\ ${ }^{1}$ Air Quality Management Resource Centre, University of West of England, UK \\ ${ }^{2}$ Bristol Green Capital Partnership, UK \\ ${ }^{3}$ Department of Applied Science, University of West of England, UK
}

\begin{abstract}
The issues surrounding successful public engagement with climate change mitigation policy and decision-making have been extensively researched and identified as barriers to long-term civic and civil engagement. The challenge of transforming our urban spaces to mitigate and adapt to climate change was a key theme of the Bristol Urban ID project, which explored the "business as usual" approaches in policy, practice and engagement that limit truly transformational actions. As part of the project, a Carbon Neutral Bristol 2050 roundtable was held with civic leaders and stakeholders. Discussions focussed on defining carbon neutrality targets, "scopes" and boundaries for Bristol, exploring the opportunity for Bristol to be a carbon neutral city leader, how to build political, business and citizen space for engagement with carbon neutrality, and the role of Bristol Green Capital Partnership (BGCP), a cross-sector network of over 800 organisation working for a sustainable city, as an enabler and facilitator of change. The findings demonstrate a need for organisations working on interconnected environmental, social and wellbeing, and economic issues in cities, such as carbon neutrality and air pollution, to communicate and collaborate. Partnership working is essential to improving city-wide engagement in carbon and air quality management decision making, and to developing integrated city sustainability management strategies that recognise co-benefits and trade-offs. A set of guidelines highlight the need to create political space for people and organisations to talk about carbon and air pollution to develop city plans.
\end{abstract}

Keywords: carbon neutral, air quality, cities, partnerships, stakeholder dialogues.

\section{INTRODUCTION}

Increasing urbanisation over the next three decades means that cities are seen as key fora for solving the challenge of mitigating climate change; over two thirds of the world's population are expected to live in cities by 2050 [1]. Bristol, UK, first committed to becoming "carbon neutral" by 2050 in a news release in 2015 following the publication of "Our Resilient Future: A Framework for Climate and Energy Security" [2]. The current mayor, Marvin Rees proposed that Bristol should run on renewable energy by 2050 as part of "the city's journey to becoming carbon neutral by 2050". Currently, City Leap - "a soft market testing exercise for potential partners in a city-scale low carbon, smart energy infrastructure programme" [3] is aiming to bring in funding for innovation in a series of energy and infrastructure projects to support the city's transformation to carbon neutrality.

Urban ID was an academic/practitioner project funded by all the UK Research Councils and Innovate UK looking at the barriers to major change in urban contexts. The project presents a set of diagnostic tools to help Bristol and other cities to understand the barriers to solving key challenges to sustainable development in the area. The diagnostic tools are based on systems thinking, co-production, participatory engagement, and resilience and learning journeys and were used to examine the Bristol Urban Area through the lens of four challenge themes: Inclusion and Equality, Health and Happiness, Mobility and Accessibility and a 
Carbon Neutral City. This paper focusses on research related to the carbon neutral city theme and in particular a Carbon Neutral Bristol 2050 round-table co-organised by Bristol Green Capital Partnership and the University of West of England, held in September 2017.

Bristol Green Capital Partnership (BGCP or Partnership) is a key non-academic part of the Urban ID project consortium, alongside both of the city's universities, the University of the West of England and the University of Bristol, Bristol City Council and South Gloucestershire Council, Bristol Health Partners and other Bristol organisations. The Partnership, as the city's environmental sustainability network, was the focus of a case study for the Urban ID project. The Partnership has around 830-member organisations from across the private, public, third and voluntary sectors located in the Bristol Urban Area and beyond and has as an aim to make "doing sustainability" easier for its members by enabling collaboration and providing space for members to come together.

The co-organised and co-facilitated Carbon Neutral Bristol 2050 roundtable was held with civic leaders and key stakeholders and focussed on a number of areas. Firstly, defining carbon neutrality in Bristol in terms of targets and "scopes". Secondly, the opportunity for Bristol as a carbon neutral city leader in the UK and internationally. Thirdly, how to engage civic and civil society with carbon neutrality by building political and citizen space for conversations, Fourthly, the role of the Partnership in promoting a Carbon Neutral Bristol Strategy.

This paper presents the outcomes form the Carbon Neutral roundtable, focussing in particular on the role of cross-sector partnerships like BGCP in setting strategies, and helping cities to create the space for stakeholder dialogues and problem-solving around the topic of carbon neutrality. This paper also considers points raised in the roundtable event on air pollution. Air pollution is recognised as an issue closely interlinked with reducing carbon emissions that needs to be discussed but which also has the potential to facilitate improved stakeholder dialogues on carbon. A set of guidelines are provided, drawing on the Carbon Neutral Bristol 2050 roundtable and the wider Urban ID project. These set out the important need for partnership working as part of city-wide engagement in decision-making and integrated management of carbon and air quality.

\section{BACKGROUND}

The issues around successful public-engagement with climate change mitigation policy and decision-making have been extensively researched, in large part, due to the recognised failure of public policy to truly bring citizens and organisations on board with the urgency and scale of the transformative action that is required. A number of reasons are suggested for why public engagement remains low [4]. Firstly, poor perception of risk, whereby issues are presented to the public in abstract, descriptive and analytical formats which do not dissuade people to shift from their prior experience and existing knowledge. Psychological distance whereby politicians and scientists focus on future consequences of climate change several decades ahead, whilst the costs of mitigation actions are more immediately seen and recognised. Negative framing where climate change solutions are sold as losses to society through higher taxes or reduced consumption and a lower quality of life. There are similar issues with communicating air quality information to the public where there is a need for better contextualising to allow people to make sense of data in relation to the real world [5].

Cities are key to addressing climate change, and this requires innovative ways to overcome the barriers to engaging people on climate change and air quality, to "bring them along" on the transformational journeys that are required. In recent years, "experimentation" has arisen as a feature of urban responses to climate change. Urban climate change experiments are a relatively new means for conducting climate governance [6] with experimentation often involving multiple forms of social and technical innovation to develop 
strategies for both technological and behavioural interventions. Urban living laboratories (ULLs) are a particular type of experimentation that brings policymakers, researchers and practitioners together to experiment with new approaches [7]. As was the case with the Urban ID project, funded under the Urban Living Partnership, ULLs can be more broadly focused on sustainability rather than specifically focussing on climate change. This can have the benefit of enabling wider discussion of co-benefits of climate change policies, increasing transparency in policies and strategies when trade-offs occur.

There are a number of main characteristics of Urban Living Labs for sustainability described in the literature [8]: They should be placed in a geographic area in "ecosystems of open 'urban' or 'civic' innovation" situated in a real urban or regional context. They should take a specific form of experimentation where innovation and learning are an explicit focus in testing ideas, solutions and policies. They should utilise co-production of knowledge and ideas, with participation and user involvement included in all stages. There also needs to be clear leadership and ownership of the experimental process. ULLs can use experimentation to construct a vision of a carbon neutral society, "empiricizing the urban landscape through monitoring and instrumentation" and feeding into local planning policy strategies [7]. A proposed addition to this process of measuring and monitoring of a city or urban area, is harnessing the knowledge of different stakeholders (or users) in order to translate or demystify data, for example, on carbon emissions or air quality, to allow people to make sense of it in in a meaningful real-world context.

The focus on co-production and participation of users in Urban Laboratories means that all key and relevant stakeholders should be included. Partnerships are involved in the majority of climate change experiments, often in a leadership role [6]. These can be vertical partnerships including different levels of government and transnational organisations, or horizontal partnerships made up of local government, civil society actors and private partners. Partnerships are important in climate change governance, in particular because they can extend the operation of the state (local government) through facilitating action by other actors [9]. In ULLs, partnerships can help to extend the range of actors included in experimentation and help ensure all relevant stakeholders are included. For example, partnerships can facilitate cooperation with the private sector and in particular SMEs - identified as a key factor in the success of policies aiming to reduce GHG emission from the transport sector in Sao Paulo [10].

There is also a need for partnerships to be boundary spanning [11]. Boundary spanning organisations as part of multi-level governance in cities are able to facilitate local sciencepolicy assessment and support local decision-making. Environmental networks are also important as knowledge networks able to harness what are often referred to as soft power characteristics related to value exchange and policy emulation [12]. Networks can ensure continuous communication and information dissemination among different sectors engaged in both technical and policy innovation. They can therefore help overcome the barriers in local government of "not my business" and "not in my term" that sees environmental issues siloed or not addressed until a more political expedient time [13]. Networks can provide forums for discussing common issues and for building substantive political support at the grass-roots level. Boundary spanning environmental networks are able to link different social and organisational worlds in order to foster innovation. They can enable two-way communication between multiple sectors and in experimentation can help integrate production of science with user needs [12].

Despite a diversity of climate change experiments, they do not always challenge established ideas about the management of resources in a city [6]. For example, there is often a separation between interventions focussed on energy consumption patterns and those 
focussed on the means of production - the energy system. The Urban ID project diagnosed the barriers to progress and identified the business as usual approaches that stop transformation. The co-production focus integrated both citizens and organisation into the production of science policy. The inclusion of the Bristol Green Capital Partnership, a key consortium partner and a boundary-spanning environmental sustainability network that brings all sectors together (the quadruple helix of academic, business, local authorities and civil society groups) has enabled wider engagement on the project with organisations across the city. In Urban ID, the inclusion of the carbon neutral city theme embedded climate change governance into the project and this particular theme was explored in a Carbon Neutral Bristol 2050 roundtable. The roundtable provided an opportunity to discuss carbon neutrality in Bristol with key stakeholders in the city with knowledge set within the appropriate geographic context to identify both technical and social innovations that can be tested in future experimentation in the city and others.

\section{WORKSHOP METHOD}

The Carbon Neutral Bristol 2050 round table was co-organised and co-facilitated by the Partnership and the University of West of England, and held with senior stakeholders from Bristol City Council, including the Council's then cabinet member for energy and waste, and organisations in Bristol.

The roundtable took the following format:

- Welcome and introductions.

- A presentation by UWE entitled "Carbon neutral what?" discussing carbon neutrality versus zero carbon definitions, in terms of emission scopes and data sources in Bristol.

- Carbon neutral city timeline activity - in breakout groups, attendees developed milestones, achievements, aspirations and ambitions up to 2050.

- Group discussion to discuss and prioritise decarbonisation actions up to 2050.

- Engaging "carbon neutral 2050" language - group discussion of the importance of a common, shared language around achieving carbon neutrality by 2050 .

- The potential role of Bristol Green Capital Partnership's members - presentation on what Partnership members can do to encourage their peers and other organisations and citizens to engage.

- Next steps and close - information about how the outputs of this workshop would be used, next steps and following up, and any final comments.

The main aim of the roundtable was to initiate discussions around the topic of "carbon neutrality" with key stakeholders in the city to highlight areas of consensus and dissonance. Fig. 1 shows the timeline for the Carbon Neutral City timeline activity.

\section{WORKSHOP OUTCOMES AND FINDINGS}

The format of the roundtable stimulated a number of discussions on carbon neutrality in Bristol and the role of the Partnership. These discussions are described in this section.

4.1 Defining carbon neutrality targets for Bristol:

The following definition of carbon neutrality was proposed at the roundtable: 


\section{Carbon Neutral Bristol 2050}

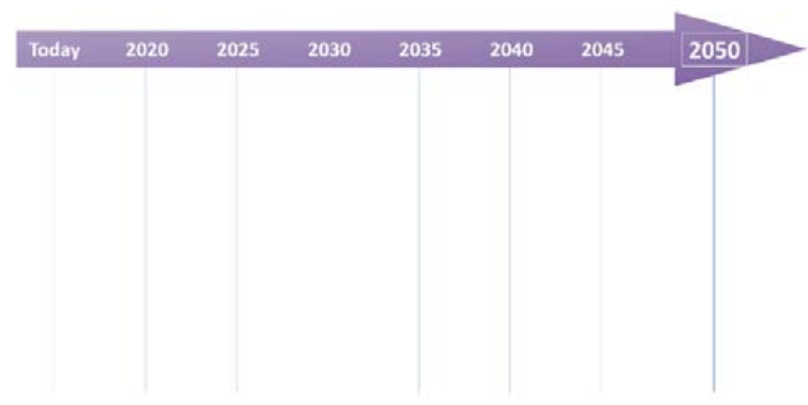

\section{URBAN = ID}

Figure 1: Timeline for Carbon Neutral Bristol Activity.

"Though wording around carbon neutrality is contested, generally it can be defined as reducing emissions to the lowest levels and then offsetting/sequestering any remaining emissions through certifiable processes."

A political need for targets was stated in the roundtable but with the proviso that they do not become the sole focus of dialogues and action. Targets do not have to be everything and Bristol can and perhaps should go beyond them, though having a target articulates a recognition that "we need to do something".

Carbon neutrality targets in Bristol's policy commitments largely refer to scope 1 and 2 emissions (direct emissions and those from purchased electricity). Arguments were put forward that scope 3 emissions (those embedded in goods and service) should not be ignored in policy because unless there is some sense of wider consumption, it can be ignored. It was suggested that city policies over time should consider scope 3 emissions to avoid a fossilisation of business-as-usual approaches and to ensure emissions related to increasing consumption are not simply off-loaded to low-income countries. The city should consider action from the perspective of an "ecosystem" that includes emissions from production outside the region

The difficulty of quantifying scope 3 emissions due to high uncertainty was raised but emerging, meaningful methodologies such as the one used in London [14], were highlighted and it was agreed that accounting would become easier in the future. Participants suggested that a focus on scopes 1 and 2 made it easier to talk about and to quantify co-benefits of carbon emission reduction, in particular, improved air quality. This links to the important ability of the city to be able to communicate the local context of emission scopes and targets to citizens and organisations.

\subsection{Bristol as a leader city}

One stakeholder proposed that Bristol may have lost its leadership position and in fact is falling behind other cities around the world and even behind other UK cities, in efforts to decarbonise. This is despite being widely seen as the UK's greenest city and formerly the 2015 European Green Capital. A question posed was what can civic society organisations in 
Bristol do to "up the ante" and recover from the possible past mistakes that have led to Bristol potentially losing its position as a decarbonisation leader?

The opportunity (and challenge) was proposed for Bristol to engage the wider city in transforming to a more sustainable city by promoting procurement best practice that includes embedded (scope 3) carbon emissions. Bristol could establish a leadership position on this with substantial co-benefits in employment creation. It was proposed that Bristol could lead the UK's core cities on low-carbon benchmarking, with Bristol already a part of the lowcarbon portfolio group. It was also suggested that there is the opportunity and challenge for Bristol to set new norms by generating its own energy, developing a sharing economy and energy democracy, and being independent. Bristol could also lead the way by developing a set of baseline design principles, which should be considered in all city plans and strategies.

It was suggested that the City's plans are always based on where we are now rather than where we need to be. This short-sightedness in planning needs to change because the strategies and ideas Bristol is setting in chain now are critical to how things change in the future but a "here and now" approach risks fossilising the current and creating barriers to future positive change. This was considered particularly pertinent in relation to technological development. There is a common interest in Bristol and other cities in how new and smart technologies develop but the process needs to be controlled to avoid unexpected outcomes leading to detrimental impacts - Bristol needs social and political control of development. The example of electric vehicles was given, where market growth is inevitable, but without consideration and control in planning and policy, growth could lead to less walking and cycling and higher levels of obesity and poor health. The upcoming (now in development), "One City Plan" [15] was highlighted as an opportunity for Bristol to lead the way on a future focused, co-produced city planning process.

\subsection{Engaging with carbon neutrality}

Roundtable attendees identified the need to manage terminological complexity around carbon neutrality to engage broader communities. Organisations in the city who are members of the Partnership are talking about issues closely related to carbon neutrality even if they are not talking about it directly (the example of Bristol Natural History Consortium was given who talk about a sustainable city rather than a carbon neutral city).

The question was posed of "how are we fertilising the ground we're imposing policy on?" both in relation to businesses and citizens. Attendees identified the need to find or create political space to discuss carbon neutrality, the interconnected issues around how we want to live and work in the future, and how to overcome barriers to transformation and decarbonisation.

For the business community this means making the way Bristol talks about carbon neutrality compatible with their objectives. Quality of life impacts and business outputs need to be communicated in conjunction in "carbon conversations" with the business sector to promote the co-benefits of action such as improved air quality and health.

For citizens, there was recognition that there will always be a subset of people who either do not care about or do not believe in climate change, but in general, "people do care". To engage as many people as possible, conversations need to be based on a narrative of hope and about achieving something better, for example, talking about a "post-combustion" society or "clean energy city" or "clean city". Dialogues with citizens should refer to physical, tangible effects rather than ideas and concepts. Roundtable participants identified that "avoiding a bad thing is a motivator but achieving something better is a stronger motivator". 
Conversations also focussed on the agency of citizens and organisation to act on climate change and how the way we talk about climate change and environmental issues compounds a lack of agency. When talking about energy and carbon dialogues with stakeholders often ask what are we going to do but never ask people what they want to do. Co-design of technological solutions was proposed as one way to engage people - by bringing them together to design solutions in focus groups, for instance. Participants identified an appetite for "open door" events that allow citizens to see how technologies work.

In terms of policy and planning, participants highlighted that there is a common assumption made by academics and politicians that people "don't need to know" the different steps and stages and should just be happy to refer to experts. To challenge this Bristol should consider what is in the "policy engagement with citizens' space" in Bristol at the moment and how this can be improved, increased and democratised, and extended to consider the environment and carbon neutrality. In addition, how can this political space extend beyond those commonly seen as engaged with "green" issues and carbon neutrality to reach different areas of the city?

\subsection{The role of Bristol Green Capital Partnership}

Participants of the roundtable agreed that the Partnership has a role to play in creating and increasing space for organisations and citizens. The Council was not considered to be best placed to open up the space needed to engage organisations and citizens in dialogues on carbon neutrality and other environmental sustainability issues such as air pollution. The Partnership is ideally placed to create space for specialists to debate and engage with members to explore questions and solve problems around carbon neutrality. The Partnership is already engaged in showcasing good practice and could also look to further develop fora for demonstrating members' ongoing activities such as member blogs.

In terms of facilitating dialogues, discussions focussed on how to get people talking and thinking about energy in different formats and fora, such as community energy schemes, community groups, and through schools and workplaces. In particular, working with young people was identified as being important in order to normalise behaviour for the future that will lead to a carbon neutral city. In the short term, it is important for the Partnership to help communicate the bigger picture to organisations and citizens across the city and link carbon neutrality with issues that may be of more immediate concern to people such as air quality and social inclusion and fuel poverty.

\section{DISCUSSION}

In terms of the barriers to transformational change in Bristol, attendees identified a number of reasons why people do not engage with carbon neutrality, many of which reflect the reasons suggested in the academic literature [4]. Terminological complexity was highlighted as an issue, as were lack of real world context and negative framing. The need for positive language when talking to citizens and organisation was proposed as a solution, with the suggestions of "Clean Air Cities" or "Post-Combustion Cities" as better terms to initiate dialogues and engage people. There was the recognition that organisations in the city, even those working in the environmental sustainability sector do not use the term carbon neutral, instead talking about a sustainable city.

An issue arises in that "carbon neutral" even with an often-contested definition is quantifiable in a way that "sustainable" is not. The aim of a carbon neutral city links to specific targets on emission reductions set at local, national and international level and can be clearly defined by a city's government inventory approaches. The roundtable identified 
the challenges in empiricising carbon neutrality for city-level experimentation [7]. Attendees did not reach a consensus on which emission scopes should be included in a carbon neutral definition for Bristol or on the boundaries of the city's control of and responsibility for emissions. A majority agreed that targets should focus on scopes 1 and 2 with a minority arguing for a greater inclusion of scope 3 . The political need for targets was identified but the overall, though not directly stated, suggestion from attendees was that carbon neutral, scopes and emissions were not the correct terms on which to engage citizens or organisations.

Air quality was proposed as a potential framing for talking about carbon that provides a real-world context, particularly with organisations where the co-benefits of climate change action and air pollution reduction were considered relatively easy to calculate and communicate. As identified in the literature there are similar issues with communicating air pollution data as climate change data so the use of air quality as a real-world framing for dialogues a carbon neutrality is something that requires further examination.

This is where the Partnership comes in. Attendees at the workshop recognised that the Partnership has a role in creating political space in the city for action, learning and dialogues on a carbon neutral city, and in agreement with the literature [9], they recognise that this is not a role for local government. The Partnership spans multiple boundaries [11] and act as a knowledge network [12], bringing specialists together with non-specialists for mutual learning. The can also continue to bring their members together to show-case good practice but can also seek out further opportunities for members to present their work, progress and knowledge related to carbon neutrality with citizens and communities. One way of doing this would be to formalise the process of bringing member organisations and citizens together to co-design technological solutions in focus groups, though this, of course, would require new sources of funding to be found. They could also support "open door" events by their members that allow citizens to see how different technologies work, related to carbon neutrality or reducing air pollution. The new member forum aims to do this by helping members to cocreate and co-support new projects.

The Partnership can help facilitate stakeholder dialogues in the city and get people talking and thinking about energy in different formats and fora. Dialogues need to challenge the business-as-usual approach in experimentation where innovations are separated, focussing on either energy supply technologies or behaviour change [6]. This can be done by bringing together Partnership member organisations working on different but interconnected environmental, social and wellbeing issues in cities, to examine the issues of carbon neutrality and air pollution, encouraging boundary spanning communication and collaboration. Problem-solving sessions should start with the question of how do we want to live and work in the future, rather than starting from a fix view on what the future should look like. At the same time, the specialism of members should be utilised to ensure carbon conversations include relevant quantified impacts for businesses and citizens and refer to physical, tangible effects rather than ideas and concepts. Finally, the Partnership and the City should not shy away from talking about either carbon or air quality. Instead, expertise should be utilised to build a better, empirical understanding of carbon neutrality and air pollution in the city, whilst at the same time co-producing a hopeful vision for the future.

\section{CONCLUSIONS}

The findings from the Carbon Neutral Bristol 2050 roundtable underline the importance of partnerships and environmental networks in city-level climate change and air quality governance. In particular, there is an important role in creating the political space for informed, collaborative, boundary spanning dialogues on carbon neutrality and the interconnected issue of air pollution. The outcomes of the roundtable and the wider Urban 
ID project also lead to a set of guidelines for facilitating stakeholder dialogues on carbon and air pollution in cities.

- Ask stakeholders how they want to live and work in the future, rather than presenting a fixed picture of a carbon neutral city

- Include specialists from different areas such as health and wellbeing, and natural environment, as well as those with particulat knowledge of energy supply and energy use.

- When referring to emission scopes or presenting carbon or air pollution data, identify meaningful and tangible impacts that locate these data sources in a real world and relevant geographic context.

- Align stakeholder dialogue sessions with "open door" events to show case innovation - both technological and social/organisational

- Set out a process for continued engagement learning and knowledge sharing following-on from stakeholder dialogue sessions.

\section{ACKNOWLEDGEMENTS}

The Urban ID project was funded as part of the Urban Living Partnership by all of the UK research councils and Innovate UK, under EPSRC grant number EP/P002137/1.

\section{REFERENCES}

[1] United Nations, United Nations Department of Economic and Social Affairs News, Online. www.un.org/development/desa/en/news/population/2018-revision-of-worldurbanization-prospects.html. Accessed on: 24 May 2018.

[2] Bristol City Council, Our Resilient Future: A Framework for Climate and Energy Security, Online. www.bristol.gov.uk/documents/20182/33423/Our+Resilient+Future + A+Framework+for+Climate+and+Energy+Security/2ee3fe3d-efa5-425a-b27114dca33517e6. Accessed on: 24 May 2018.

[3] Bristol City Council, City Leap Prospectus, Online. www.energyservicebristol.co.uk/ wp-content/pdf/City_Leap_Prospectus\%204-5-18.pdf. Accessed on: 24 May 2018.

[4] van der Linden, S., Maibach, E. \& Leiserowitz, A., Improving public engagement with climate change: Five "best practice" insights from psychological science. Perspectives on Psychological Science, 10(6), pp. 758-763, 2015.

[5] Bickerstaff, K. \& Walker, G., Clearing the smog? Public responses to air-quality information. Local Environment, 4(3), pp. 279-294, 1999.

[6] Broto, V.C. \& Bulkeley, H., A survey of urban climate change experiments in 100 cities. Global Environmental Change, 23(1), pp. 92-102, 2013.

[7] Evans, J. \& Karvonen, A., "Give Me a Laboratory and I Will Lower Your Carbon Footprint!"-Urban laboratories and the governance of low-carbon futures. International Journal of Urban and Regional Research, 38(2), pp. 413-430, 2014.

[8] Voytenko, Y., McCormick, K., Evans, J. \& Schliwa, G., Urban living labs for sustainability and low carbon cities in Europe: Towards a research agenda. Journal of Cleaner Production, 123, pp. 45-54, 2016.

[9] Kern, K. \& Bulkeley, H., Cities, Europeanization and multi-level governance: governing climate change through transnational municipal networks. JCMS: Journal of Common Market Studies, 47(2), pp. 309-332, 2009.

[10] Setzer, J. \& Biderman, R., Increasing participation in climate policy implementation: a case for engaging SMEs from the transport sector in the city of São Paulo. Environment and Planning C: Government and Policy, 31(5), pp. 806-821, 2013. 
[11] Corfee-Morlot, J., Cochran, I., Hallegatte, S. \& Teasdale, P.J., Multilevel risk governance and urban adaptation policy. Climatic change, 104(1), pp. 169-197, 2011.

[12] Feldman, D.L., The future of environmental networks - Governance and civil society in a global context. Futures, 44(9), pp.787-796, 2012.

[13] Azevedo, I., Delarue, E. \& Meeus, L., Mobilizing cities towards a low-carbon future: Tambourines, carrots and sticks. Energy Policy, 61, pp. 894-900, 2013.

[14] Greater London Authority, Assessing London's Indirect Carbon Emissions: Summary of the application of the BSI PAS 2070 standard to London, 2014. https://www.london.gov.uk/sites/default/files/assessing_londons_indirect_carbon_em issions_2010_2014.pdf. Accessed on: 29 May 2018.

[15] Bristol City Council, Creating a vision for Bristol: One City Plan. News Release, 2015. http://news.bristol.gov.uk/creating_a_vision_for_bristol_one_city_p. lan. Accessed on: 29 May 2018. 